\title{
Interview with Prof. J. Delaire by Dr. F. de Brondeau About Mandibular Prognathism Syndrome
}

\author{
F. de Brondeau \\ University Lecturer-Hospital Practitioner-University of Bordeaux
}

In July 1970, in the Dento-Facial Orthopedics Journal, a conversation was published between the orthodontist, L. Muller, and the surgeon, J. Delaire, concerning mandibular prognathism. This was at the time the Delaire mask was invented, 46 years ago! This topic remains current even though our management of prognathisms is now more adapted to their different forms.

The problem of therapeutic limits remains a major problem. It is thanks to his work that Professor J. Delaire shows that there are few cases of hereditary prognathism. The purpose of the treatments is to re-establish a balanced growth pattern that factors in the patient's transfrontal pattern.

Dr. de Brondeau: The definition of mandibular prognathism syndrome that you have given summarizes the complexity of this craniocervicofacial anomaly and the variety of different forms that this syndrome can take. Is the classification you have established in 1996 still valid according to you?

Prof. Delaire: The classification I had given had been presented at the Bordeaux
Congress under the chairmanship of Prof. P. Caix. The architectural analysis had allowed me to establish different forms of prognathisms: A true prognathism with mandibular hypertrophy forward shifting, hypotrophy of the maxilla in all their forms (brachymaxillia, retroposition ...), and mixed forms and Class-III cranial disorders.

Dr. de Brondeau: So, for you, this classification remains topical? Because, in the majority of articles it is given as a reference.

Prof. Delaire: Yes, it is given as a reference, but we must not forget that it is very therapeutically significant, especially when the subject is aged $\leq 10-11$ years. If the patient presents with retromaxillia, it is possible to act in most cases, by acting on the maxilla (with expansion and advancement). Whereas in a subject at the end of pubertal growth, we are obligated, even if it was a functional form at the beginning, to perform a surgical correction.

Dr. de Brondeau: What would be the best therapeutic strategy for you in relation to mandibular prognathism?

\section{Address for correspondence:}

François de Brondeau

3 bis rue Condorcet

33150 Cenon

E-mail: fdb33@aol.com

Article Received: 11-08-2016. Accepted for publication: 20-11-2016.

This is an Open Access article distributed under the terms of the Creative Commons Attribution License (http://creativecommons.org/licenses/by/4.0), which permits unrestricted use, distribution, and reproduction in any medium, provided the original work is properly cited. 
Prof. Delaire: The therapeutic strategy will be fundamentally variable according to the diagnosis. A diagnosis is an overall diagnosis of a group. For Class-III cases, this means that the mandible is further forward in relation to the upper maxilla.

Treatment will depend on the etiology, but a diagnosis is too often a general diagnosis and not a true background diagnosis, which must include an etiology! True diagnosis includes diagnosis and etiopathology, thus implying an appropriate therapeutic intervention.

For example, with regard to the mandible, if you make the diagnosis of functional mandibular prognathism in a subject with lingual dysfunctions that push the mandible forward, the treatment will vary depending on age. If it is before the patient has stopped growing, this is going to be a vigorous orthopedic treatment of obtaining an expansion and a maxillary advancement, and to some extent a somewhat bridled mandible. Thereafter, a mandibular therapy will be necessary to try to change the shape of the mandible, so that it bends, closes, and eventually the subject regains a good occlusal function, swallowing, and physiological posture of the tongue. Thereafter, the patient may be in a position sufficiently stable for the maxillary anomalies to fade, eventually leading to the disappearance of prognathism. In addition, you can avoid surgery. If, on the contrary, the patient is aged $>11$ years, the functional part is only partial, and there is a certain tendency of the skeletal state to favor the prognathism at that time, the surgery will be the standard option. Among these cases, some have a reduction in the size of the cranial base, a typology like that of the "Habsburg" jaw. You may have in many cases in Austria of prognathism that are caused by a shortening of the distance between the eyes and the ears. The mandible will then be placed in a position that will be more anterior than normal, and if the subjects have any ventilation disorders, the maxilla is too far back and is accompanied by a mandibular prognathism that can be considerable. That is the whole problem of the Habsburgs, who had a constitutional, familial predisposition, and they often presented with ventilatory disorders!

In the absence of ventilatory disorders, Melsen showed that women were less frequently affected and often developed functional and esthetically acceptable Class-III dental structures. On the other hand, in men, such as those in the Habsburgs lineage of the Kings of Spain, the mandibular prognathism was considerable and very much associated with ventilatory status and tongue position. This situation is therefore more complex, as there are several determinant constitutional and age factors that complicate the prognosis.

So, the question you are asking me is very difficult to answer, because it depends on the type of syndrome:

- Is it a secondary fundamental syndrome or a cranial malformation (very difficult to treat)?

- Or is it a syndrome where there is a certain degree of hereditary influence? If there is a significant amount of hereditary influence, you may have sufficient data to ensure that surgery is not mandatory.

In other cases, mandatory interventions must be planned involving mandibular retraction and maxillary advancement. 
Dr. de Brondeau: When faced with a Class-III patient, if the option is surgical, what are the best techniques for each of the different forms? It would seem that the advanced maxillary interventions are currently preferred because they lead to a more stable result. Even if surgeons base their analysis on your architectural analysis, when faced with forms associated with a mandibular anomaly, will they be more tempted to perform maxillary interventions. What do you think of this option?

Prof. Delaire: I think they are right because the contribution of the mandible toward lingual function is very limited. Would you aim for perfect lingual functioning to ensure the mandible contributes to the same extent as the maxilla? That is not safe!

And indeed, you will have much more stability in cases of maxillary advancement compared to the mandibular procedures which you keep in stable position, and which will not tend to move in the sagittal plane if you have performed a moderate retraction.

When you are performing a significant mandibular retraction, you will be faced with lingual dysfunctions, which tend to lead to relapses. It is in these situations that an osteotomy favoring the maxilla seems to be a preferable option.

Another important point is to see if the patient is breathing well, because if mouth breathing is not corrected, there will be all the factors responsible for a recurrence of the skeletal shift. This will be partly due to the maxilla, but especially due to the mandible.

Dr. de Brondeau: In reference to past years, and the invention of the Delaire mask, which is the best mask that can be prescribed? It is one of the most es- sential tools for the orthodontist. What advice can you give, for its indication and use? Some clinicians will recommend wearing it at the end of the day, whereas you would only recommend wearing it at night?

Prof. Delaire: The mask is not always needed.

If the patient is young, i.e., aged 4-5 years with temporary dentition, it is theoretically possible to perform a treatment that changes the position of the tongue, so that it goes back into the oral cavity, and possibly perform a maxillary expansion if necessary. Thus, if the tongue rests well when swallowing and chewing, it is possible to avoid maxillary retraction. Thus, the treatment our Class-III patient almost always needs a maxillary retraction at this age. This has been demonstrated by many authors, including McNamara, apart from myself. Indeed, in children aged $<6$ years, it is almost always a case of retromaxillia. So, this is where we need to focus all our efforts, and the maxilla, at this stage, is easy to develop. So there is not always need for mask traction, which begins in patients aged around 6-7 years.

Beforehand, you may want to consider other treatments, i.e., ELN or classic lingual ramp; but always choose devices that place the child's tongue back in the palate, with devices that can be used all day.

Other practitioners continue to prescribe what I was doing - that is, wearing the mask, but only at night. This has the big advantage of not tiring out the child and not making them look ridiculous in front of others! They put on the mask when they fall asleep, they take it out when they up and Petrovic has stated: "The mask does not need to be 
worn all night." It is enough to put it in 3-4 $\mathrm{h}$ at the beginning of the night, because it is then that somatotropic hormones are secreted. This is enough because the stimulus continues to be exerted through the night. I think that is still valid. Maybe it is a little old-fashioned, just like the author! If I still had patients, that is what I would do. If that is not enough, you have to move on. On the other hand, in my opinion, it is imperative to do so before 10 years of age because, if we allow the jawbone to contract, the habits become much more entrenched and the results are less satisfactory.

Looking at all the cases I treated, in virtually every treatment that I waited until the patient was 11-12 years old, I did not have a perfect result. When a treatment begins after the age of 11-12 years, it is necessary to think about distraction and about expansion! I believe it is a step-by-step treatment based on age to get a stable treatment!

Dr. de Brondeau: One of the purposes of our interview was to determine how your thinking has changed since your exchange with Mrs. Muller.

Prof. Delaire: Mrs. Muller interviewed me in July 1970. This was before the publication of the architectural analysis. I had thus not become aware of the many factors responsible for mandibular prognathism, particularly the spinal and cranial factors.

Currently, for making my therapeutic prognosis, in particular my orthodontic prognosis, I look to see if the spine is normal following my treatment.

If the spine cannot be realigned, I know the treatment is going to be very difficult. Thus, I have an possibly unfavorable prognosis if I wait. Thus, to ensure that it does not get too much worse, a surgery is required. The next question is-How old? And given the esthetic, functional, and social anomaly of mandibular prognathism in the sensitive phase of childhood, I aim to intervene sooner.

I still have emotional testimonies of young girls who have become women, married, with children, who write to me every year, telling me that I "saved their lives" by operating on them so young, because I changed their way of life. It is therefore necessary to reason as a surgeon and from a social point of view also. Emotions must be considered because orthodontists have a great role to play and in some cases, we must choose new solutions-for example, between the end of orthopedic treatment where often nothing is done, and the start of a surgical process that will be performed for someone whose age is 16-18 years.

There are surgeons who prefer not to operate before age 18 years to avoid relapses. They are not entirely wrong. However, in some cases of moderate prognathism in patients aged approximately 13 years on the verge of an osteotomy, I will perform osteotomies without immediate displacement, but with gradual displacements aided by the mask-i.e., intermediate distractions.

In Montpellier, Professor Souyris treated fractures (by elastic bimaxillary blockade during consolidation) in the best possible position. Generally, he had no relapses and the results were much better than we imagined. After the osteotomies, he would use wire fixation. If a slight adjustment of an imperfect occlusion was required, he used elastic intermaxillary traction as soon as he discovered that 
the occlusion was deteriorating, thus catching up with the condition. It was an empirical solution, but it was one that ensured better results in some cases without the need for a forced fixation in a position that ultimately will not necessarily be the right one according to the occlusal status.

I have doubts regarding the validity of this technique, which I am trying to pass on to the surgeons.

In fact, I try to position teeth in relation to the mandible and the maxilla in such a way so that they remain stable.

I do not think the current doctrine that "I sort my teeth out perfectly before surgery and my surgical outcome will depend on the orthodontics" is the truth!

Now, to perform surgeries first, I think it is a good trend, but it is a new trend. When I said that we had to change the position of the bases before changing the position of the teeth, no one listened to me. I learned that such surgeries were performed only a short time ago, and I was happy to hear it. But not everyone does it yet.

Dr. de Brondeau: Do you have anything else to add?

Prof. Delaire: I will bring up a few questions raised by Mrs. Muller.

I criticized the fact that we spoke a lot about mandibular prognathism but we dealt with maxillary retrognathism more often. This must be corrected by a maxillary advancement in a young subject and not by mandibular modifications. The mandibular advancement can be modified by making the sides smaller by using a Gudin plate. So, I believe that the indications of sagittal osteotomies in young subjects in mild cases of mandibular prognathism are somewhat less frequent than what they used to be.

At what age?

In maxillary cases, at age 13-15 years after the proper positioning of the upper canines. In mandibular cases on the other hand, it is necessary to wait longer because the tongue continues to develop until the age of 18 years, which is when wisdom teeth begin to erupt; thus, there is still mandibular growth. Therefore, mandibular intervention before the patient reaches age of 18 years should be avoided.

Do you have several surgical techniques? Of course, depending on the diagnosis of anomalies!

For example, in hypercondylias, I take care of the condyles in isolation. Many delay this surgery of ablating the condyle in an isolated way, as they wait for the cessation of its growth. And at that time, they do it in four parts each at the mandibular angle and the maxillary levels so as to divert the maxilla. But for me, from the age of 12 years, I remove the condyle and only on one side. Removing the right amount is often enough. Because there is no more growth on this side, the other side compensates, and the maxilla reorients. This technique has not been supported by studies, and I regret that.

Conversely, in the hypocondylia, lengthening the condyle, on one side at the right amount, often suffices to make the mandible, and thus the face, more symmetrical. A single osteotomy for elongation with a condylar graft will balance the whole face in adolescence.

Glossectomy or not?

Formerly, it was often necessary in cases of sagittal mandibular retraction, because rehabilitation was not the 
standard practice. Now it is exceptional even in cases of associated osteotomies.

The technique: I did it at the end of the operation at the anterior level while holding it in position, so as to be sure to have resected enough and that the tongue would not move back so as not to result in ventilatory problems.

I completely agree that glossectomies are no longer relevant! They should only be used in exceptional circumstances-for example in cases where the tongue is the cause of the problem. If this is the case, it is necessary to intervene very early, for example in Beckwith-Wiedemann syndrome, characterized by a large tongue, with the mandibular hypertrophy
I performed early glossectomies in children aged $4-5$ years, and the results were excellent. But these are pathological and very special cases.

In most cases, these are dysfunctions, and rehabilitation can be used as a substitute! The method I was able to initiate and develop with Madame Fournier proves to be a recognized and indispensable technique at present, both before and after the surgical intervention.

Interview conducted on September 12, 2016 in Nantes with Prof. Jean Delaire, by Margaux Montigny and Mathilde Tsang-Tung.

Conflict of interest: The author states there is no conflict of interest. 